Review

\title{
A Bilingual Advantage on Word Learning-Factors Influence on Lexical Development of Bilinguals
}

\author{
${ }^{1}$ Ning Cao and ${ }^{2}$ Guanying Chen \\ ${ }^{1}$ Department of Learning and Instructions, University at Buffalo, State University of New York, Buffalo, NY 14260, USA \\ ${ }^{2}$ School of Chemistry and Chemical Engineering, Harbin Institute of Technology, Harbin, Heilongjiang 150001, China
}

\author{
Article history \\ Received: 22-04-2020 \\ Revised: 06-06-2020 \\ Accepted: 06-07-2020 \\ Corresponding Author: \\ Ning Cao \\ Department of Learning and \\ Instructions, University at \\ Buffalo, State University of \\ New York, Buffalo, NY 14260, \\ USA \\ Email: ningcao@buffalo.edu
}

\begin{abstract}
Lexical development is the changes that occur in vocabulary knowledge. The central role of the lexicon in language and vocabulary development makes it an integral aspect in the study of bilingualism. In recent years, there are many studies on lexical development in bilinguals. By reviewing these related studies, it reveals that the age of acquisition, executive function and early language environment are three significant factors contributing to individual differences in vocabulary growth and lexical development. The primary purpose of this study is to profile lexical development in bilinguals and to examine the effects of age, executive function and early language environment on lexical development. Also, a bilingual advantage for word learning is viewed so as to exam if there is any advantage of bilinguals in lexical development.
\end{abstract}

Keywords: Lexical Development, Bilinguals, Effects of Age, Executive Function, Early Language Environment

\section{Introduction}

\section{Factors Influence on Bilingual Lexical Development}

Over the last decades, many studies and researches concerning the field of bilinguals have emerged. It indicates that the age of acquisition, executive function and early language environment are three crucial factors affect lexical acquisition and development in bilinguals.

\section{Age Acquisition Effects on Language Proficiency}

In its broad sense, the age of acquisition refers to the age at which a word, concept or skill is learned. Generally speaking, age is a crucial factor in language learning and the age of acquisition plays an important role in lexical development in bilinguals.

Those early childhood years have been described as a 'critical period' for language acquisition, it is a time when language can be acquired much more easily than that when the critical period has passed (Marinova-Todd et al., 2000).

Yamazaki et al. (1997) recommends that the quality of lexical representations is influenced by the age at which they're learned and that the effects of age of spoken and written acquisition reflect the influence of those variables upon the speech output lexicon and the visual input lexicon respectively.
Also, most of the prior studies involved a comparison between words learned in early childhood and words learned in later childhood or adulthood with a purpose to observe the age of acquisition effects. Some studies show that all other things being equal, words learned early in life can be recognized and produced faster than later-learned words (Izura and Ellis, 2002).

In Kaushanskaya and Marian (2007)'s study, the authors compared monolingual English-speaking adults, early English-Spanish bilinguals and late EnglishSpanish bilinguals and examined the effect of L2 acquisition age on the development of bilingual advantage for novel word learning. The findings show that it's not late bilingual, but early bilinguals outperformed monolinguals on the word-learning task.

Since the age of acquisition does have some effects on lexical development, some researchers tried to seek out the reasons for the age acquisition effect. Brown and Watson (1987) advised that the age of acquisition effect is because of differences in the quality of phonological representations that early and late acquired words enjoy (Brown and Watson, 1987). They proposed that words acquired earlier are represented in a complete phonological form whereas late acquired words are phonologically fragmented (Brown and Watson, 1987).

On the other hand, Ellis and Lambon (2000) proposed an alternative explanation for the age of acquisition effect. They thought that early learned words 
are recognized and produced faster than later learned words. The researchers pointed out that the age of acquisition effect is a natural property of connectionist models trained by back-propagation when patterns are introduced at different points into training and learning of early and late patterns is cumulative and interleaved (Ellis and Lambon, 2000).

However, there is an argument on if attained language proficiency is more important than the age of acquisition. In the study of (Elston-Güttler et al., 2005), the authors used a similar paradigm to evaluate the effect of the early and late acquisition of L2 in highly proficient bilinguals. They argued that attained proficiency is more important than the age of acquisition. The findings suggest that, at least for pairs of L1 and L2 languages that are fairly close, attained proficiency is more important than the age of acquisition as a determinant of the cortical representation of L2 (Elston-Güttler et al., 2005).

In contrast, Silverberg and Samuel (2004) assessed the effects of second language proficiency and the age of L2 acquisition. In this study, three types of bilinguals are compared: Early L2 learners, late less proficient L2 learners and late highly proficient L2 learners. A lexical decision priming paradigm and three types of L2-L1 priming conditions were used, including semantic primes, mediated form primes and form primes. It's found that highly proficient late learners showed inhibitory effects of form primes, whereas the less proficient group produced no priming effects of any type (Silverberg and Samuel, 2004). It reveals that the age of L2 acquisition has a major influence on how bilinguals express and acquire words in their second language.

What's more, Mayo et al. (1997) also conducted a study to determine how the age of acquisition influences the perception of L2 speech. The authors used Speech Perception in Noise (SPIN) test which consists of eight lists of 50 short sentences to check the early and late Mexican-Spanish-speaking bilinguals and American-English monolinguals. Results show that non-native listeners' ability to discriminate secondlanguage speech in the presence of noise is affected by the language acquisition age though they have developed a high level of fluency. It emphasizes that learning a second language at an early age is more important than attained language proficiency.

\section{Executive Function on Lexical Development}

Besides the age of acquisition, executive function is also one crucial element that influences on lexical development. The executive system is a theorized cognitive system in psychology that controls and manages other cognitive processes (Executive System, 2008). It is a general term for cognitive processes and is responsible for processes that are sometimes referred to as the executive functions, supervisory attentional system, or cognitive control. These functions are largely carried out by prefrontal areas of the frontal lobe (Executive System, 2008).

There are several studies focus on the executive function on lexical development. Some studies conducted researches on the brain bases of word production. Bookheimer (2002) have identified regions in both the frontal and temporal lobes that are crucial for language processing. Moreover, some studies have identified a region in the inferior temporal lobe, bordering on the occipital cortex, which is crucial for the processing of objects. Some researchers believed that a single exposure to an object can produce long-lasting behavioral change. van Turennout et al. (2000)'s study, by using event-related functional Magnetic Resonance Imaging (fMRI), they provide evidence for long-lasting changes in cortical activity associated with perceiving and naming objects. In posterior regions, they observed an immediate and long-lasting decrease in neural activity after brief exposure to nameable and nonsense objects (van Turennout et al., 2000). It reveals that the formation of sparser, yet more object-form-specific, representations in posterior regions and experience-induced reorganization of the brain circuitry underlying lexical retrieval in anterior regions (van Turennout et al., 2000).

On the other hand, some studies start examining the effect of bilingualism on cognitive development and specifically, executive function. In the study of Bialystok et al. (2004), it is found that bilinguals' ability to control processing decreases less with age than monolinguals and the bilinguals have an advantage in complex processing requiring executive control. Also, bilingual children gain executive control functions earlier than monolinguals and bilingual adults have more executive resources available when executive demands become especially complex (Bialystok, 2007). Echo to Bialystok's research, Carlson and Meltzoff (2008) also point out that native bilingual children perform significantly better on the executive function after accounting for vocabulary differences.

\section{The Role of Language Environment on Bilinguals' Lexical Development}

According to prior studies, early language experience and living environment is one crucial factor contributing to individual differences in vocabulary growth and lexical development in bilinguals.

Existing evidence show that lexical development is not generally compromised in bilinguals and the large differences in children's language acquisition were tightly related to the differences in children's language learning experiences and living environment.

In Hart and Risley (1995)'s study, the authors wanted to explore why children from low-income homes remain 
well behind their peers from more economically advantaged homes after several years in school, though they have equal opportunity in preschool programs. They found that by the age of three, the recorded spoken vocabularies of the children from the professional families were larger than those of the parents in the welfare families. Between welfare parents and professional parents, there was a difference of about 300 words spoken per hour. It suggests that children can have a better chance to succeed at school if parents interact with children positively and spend time teaching their kids vocabulary, literacy and language concepts.

Although some evidence show that there are some individual differences among bilingual children, some researchers point out, in each of their two languages, young bilinguals generally follow a developmental trajectory that is similar to that of monolinguals (Pearson et al., 1993). However, in the process of early development, it is not necessary that those children who produce many words in their first language are those who produce the same amount of words in their second language. According to prior studies, the unbalanced outcomes in early vocabulary among bilingual children are likely because of that they are typically exposed to the two languages to different degrees or that exposure to each language is distributed over different learning contexts, such as home, daycare or school (Pearson et al., 1993). Actually, there is an interference between the first language use at home and the second language use at school or daycare.

Hart and Risley (1995) stated that there are three predictors of vocabulary for English-speaking children, including literacy practices at home, family socioeconomic status as well as the frequency with which parents talk to their children. Undoubtedly, these predictors also can be used in bilinguals' lexical development. What's more, Padilla et al. (1991) suggested that factors such as immigration age, social class and educational level, etc. also influence on bilinguals' language use and lexical development.

However, on one hand, some children, despite the fact that they were born to bilingual parents, end up speaking only English. On the other hand, others, who live at homes where the L1 is used exclusively or is greatly valued and used for social purposes with family and friends, are more likely to develop bilingual abilities (Grosjean, 1982). Besides other sociocultural and individual factors influence the language used at home, this matches previous research findings that native language maintenance across generations is influenced by the language used at home (Pearson, 2002). Reese et al. (2000), it's found that family factors, including family literacy practices, grandparents' educational level as well as parents' socioeconomic can predict both early Spanish literacy and later English reading. Therefore, it recommends to encourage families to provide home literacy activities as well as formal preschool experiences.

Similarly, in Duursma et al. (2007)'s study, it's found that students who received their initial literacy instruction in Spanish and whose father preferred to speak English tend to have higher scores on English vocabulary. On average, children from families who prefer to use English at home tend to have higher English proficiency, on the contrary, children from families with a preference for Spanish at home tend to have higher Spanish proficiency scores. It indicates that parental language preferences at home were related to children's linguistic proficiency in both first and second languages.

\section{A Bilingual Advantage for Word Learning}

Since there are many factors affect bilinguals' lexical development, a question arises naturally; what's the difference between bilinguals and monolinguals in lexical development?

A comparable bilingual advantage was reported by (Kroll et al., 2002), who pointed out that English-Spanish and English-French bilinguals outperformed monolinguals on a task that involves verbal working memory. In this article, the authors found that bilingual learners were faster and more correction-prone to name and to translate words in both English and the second language.

What's more, studies consistently report bilingual advantages in nonverbal executive control tasks, both for children and adults. It shows that bilinguals not only have an advantage over monolinguals in nonlinguistic tasks involving executive control, but also resolve various types of response conflict faster than monolinguals and this bilingual advantage generally increased with age (Bialystok et al., 2006).

In addition, bilinguals appear to have an advantage over monolinguals in phonological development. In Buck's and Genesee (1995)'s study, the participants were English-speaking children who were attending French schools, they were given a battery of phonological awareness tests in kindergarten and in grade I. Results shows that Spanish-English bilinguals performed better than English-speaking monolinguals. Echo to Buck and Genesee's study, Papagno and Vallar (1995) also found that bilinguals performed better on tests of phonological short-term memory and on a foreign-word learning task than monolinguals.

Moreover, it also reveals a bilingual advantage in cognitive function by examining word learning in bilingual and multilingual adults. van Hell and Mahn (1997) stated that experienced language learners outperformed novice language learners in both the number of retained foreign words and in the speed of their retrieval (van Hell and Mahn, 1997). 
With a purpose to examine the age of acquisition effects in the development of the bilingual advantage for word-learning, Blumenfeld and Marian (2007) compared highly-proficient English-Spanish bilinguals to English monolingual speakers by using a novel word-learning task. The findings show that early bilinguals, but not late bilinguals, outperformed monolinguals on the word-learning task. The examination of age acquisition effect in the development of the bilingual advantage for foreign word learning suggests that earlier acquisition age increases bilingual advantage. It is also found that the late bilinguals with longer exposure to Spanish outperformed late bilinguals with a shorter exposure to Spanish. These findings suggest that it may be possible to dissociate the age acquisition effects from length-ofexposure effects in the development of bilingual advantage (Blumenfeld and Marian, 2007).

\section{Conclusion}

This paper states that the age of acquisition, executive function and early language environment are three crucial factors contribute to the lexical development in bilinguals. Words learned early in life can be recognized and produced faster than these words learned later. Besides, the identified regions in both the frontal and temporal lobes are important for language processing and early language experiences result in individual differences in vocabulary growth and lexical development. It also shows bilinguals have an advantage over monolinguals in both linguistic and nonlinguistic tasks involving executive control, phonological development, cognitive function as well as word learning.

Undoubtedly, these findings will definitely give some practical and theoretical implications to researchers who aim to conduct a study on lexical development and language learning in bilinguals. It suggests that further researches should pay more attention to some other factors, such as cultural environment, individual differences and language ability, etc. which also play a significant role in the lexical development in bilinguals.

\section{Author's Contributions}

Ning Cao: Organize and draft the whole manuscript.

Guanying Chen: Edit the language and provide valuable discussions on the content and structure.

\section{Ethics}

This article is original and contains unpublished material. The corresponding author confirms that all of the other authors have read and approved the manuscript and no ethical issues involved.

\section{References}

Bialystok, E. (2007). Cognitive effects of bilingualism: How linguistic experience leads to cognitive change. International journal of Bilingual education and bilingualism, 10(3), 210-223.

Bialystok, E., Craik, F. I., Klein, R. and Viswanathan, M. (2004). Bilingualism, aging and cognitive control: evidence from the Simon task. Psychology and aging, 19(2), 290.

Bialystok, E., Craik, F. I. and Ryan, J. (2006). Executive control in a modified antisaccade task: Effects of aging and bilingualism. Journal of experimental psychology: Learning, Memory and Cognition, 32(6), 1341.

Blumenfeld, H. K. and Marian, V. (2007). Constraints on parallel activation in bilingual spoken language processing: Examining proficiency and lexical status using eye-tracking. Language and cognitive processes, 22(5), 633-660.

Bookheimer, S. (2002). Functional MRI of language: new approaches to understanding the cortical organization of semantic processing. Annual review of neuroscience, 25(1), 151-188.

Brown, G. D. and Watson, F. L. (1987). First in, first out: Word learning age and spoken word frequency as predictors of word familiarity and word naming latency. Memory and cognition, 15(3), 208-216.

Buck, M. and Genesee, F. (1995). Phonological awareness in young second language learners. Journal of child Language, 22(2), 307-324.

Carlson, S. M. and Meltzoff, A. N. (2008). Bilingual experience and executive functioning in young children. Developmental science, 11(2), 282-298.

Duursma, E., Romero-Contreras, S., Szuber, A., Proctor, P., Snow, C., August, D. and Calderón, M. (2007). The role of home literacy and language environment on bilinguals' English and Spanish vocabulary development. Applied Psycholinguistics, 28(1), 171-190.

Ellis, A. W. and Lambon Ralph, M. A. (2000). Age of acquisition effects in adult lexical processing reflect loss of plasticity in maturing systems: Insights from connectionist networks. Journal of Experimental Psychology: Learning, memory and cognition, 26(5), 1103.

Elston-Güttler, K. E., Paulmann, S. and Kotz, S. A. (2005). Who's in control? Proficiency and L1 influence on L2 processing. Journal of cognitive neuroscience, 17(10), 1593-1610.

Executive System, (2008). Wikipedia.

Grosjean, F. (1982). Life with two languages: An introduction to bilingualism. Harvard University Press. 
Hart, B. and Risley, T. R. (1995). Meaningful differences in the everyday experience of young American children. Paul H Brookes Publishing.

Izura, C. and Ellis, A. W. (2002). Age of acquisition effects in word recognition and production in first and second languages. Psicológica, 23(2).

Kaushanskaya, M. and Marian, V. (2007). Age-ofacquisition effects in the development of a bilingual advantage for word learning. In Proceedings of the 32nd annual Boston University conference on language development (pp. 213-24).

Kroll, J. F., Michael, E., Tokowicz, N. and Dufour, R. (2002). The development of lexical fluency in a second language. Second language research, 18(2), 137-171.

Marinova-Todd, S. H., Marshall, D. B. and Snow, C. E. (2000). Three misconceptions about age and second language acquisition. TESOL Quarterly, 34(1), 9-34.

Mayo, L. H., Florentine, M. and Buus, S. (1997). Age of second-language acquisition and perception of speech in noise. Journal of speech, language and hearing research, 40(3), 686-693.

Padilla, A. M., Lindholm, K. J., Chen, A., Durán, R., Hakuta, K., Lambert, W. and Tucker, G. R. (1991). The English-only movement: Myths, reality and implications for psychology. American Psychologist, 46(2), 120.

Papagno, C. and Vallar, G. (1995). Verbal short-term memory and vocabulary learning in polyglots. The Quarterly Journal of Experimental Psychology Section A, 48(1), 98-107.
Pearson, B.Z., (2002). Bilingual Infants. In: M. and M. Paez (Eds.), Latino Remaking America, SuarezOrozco, (pp: 306-320), University of California Press and David Rockefeller Center for Latin American Studies, Harvard University, Los Angeles.

Pearson, B. Z., Fernández, S. and Oller, D. K. (1993). Lexical development in simultaneous bilingual infants: Comparison to monolinguals. Language Learning, 43(1), 93-120.

Reese, L., Garnier, H., Gallimore, R. and Goldenberg, C. (2000). Longitudinal analysis of the antecedents of emergent Spanish literacy and middle-school English reading achievement of Spanish-speaking students. American Educational Research Journal, 37(3), 633-662.

Silverberg, S. and Samuel, A. G. (2004). The effect of age of second language acquisition on the representation and processing of second language words. Journal of memory and language, 51(3), 381-398.

van Hell, J. G. and Mahn, A. C., (1997). Keyword mnemonics versus rote rehearsal: Learning concrete and abstract foreign words by experienced and inexperienced learners. Language Learning.

van Turennout, M., Ellmore, T. and Martin, A. (2000). Long-lasting cortical plasticity in the object naming system. Nature neuroscience, 3(12), 1329-1334.

Yamazaki, M., Ellis, A. W., Morrison, C. M. and Ralph, M. A. L. (1997). Two age of acquisition effects in the reading of Japanese Kanji. British Journal of Psychology, 88(3), 407-421. 